\title{
SYNTHESIS AND CHARACTERIZATION OF A DEHYDROGENATION PRODUCT ARISING FROM THE OXIDATION OF AMINOETHYLCYSTEINE KETIMINE DECARBOXILATED DIMER
}

\author{
Alberto Macone, ${ }^{\dagger}$ Aldo Caiazzo,${ }^{\ddagger}$ Antonio Antonucci, ${ }^{\dagger}$ Igor Fochi,${ }^{\S}$ Mirella Nardini,, \\ Silvestro Duprè, ${ }^{\dagger}$ Rosa Marina Matarese ${ }^{\dagger *}$
}

\begin{abstract}
$\dagger$ Department of Biochemical Sciences "A. Rossi-Fanelli" and National Research Council Institute of Molecular Biology and Pathology, University of Rome "La Sapienza", Piazzale Aldo Moro 5, 00185 Rome, Italy. ${ }^{\ddagger}$ Van’t Hoff Institute for Molecular Sciences, Faculty of Science, University of Amsterdam, Nieuwe Achtergracht 129, 1018 WS Amsterdam, The Netherlands. ${ }^{\S}$ Toxicological Chemistry Unit of the Department of Environment and Primary Prevention, Italian National Institute for Health, Viale Regina Elena 299, 00161 Rome, Italy. "National Institute for Food and Nutrition Research, Via Ardeatina 546, 00178 Rome, Italy.
\end{abstract}

\section{Supporting information}

$\begin{array}{lll}\text { Figure S1. GC/MS analysis of compound 2a } & \text { S2 }\end{array}$

Figure S2. High Resolution Mass Spectrum of compound 2b S3

Figure S3. $\quad{ }^{1} \mathrm{H}-\mathrm{NMR}$ spectrum of compound $\mathbf{2 b}\left(500 \mathrm{MHz}, \mathrm{CDCl}_{3}\right) \quad \mathrm{S} 4$

Figure S4. $\quad{ }^{13} \mathrm{C}-\mathrm{NMR}$ spectrum of compound $\mathbf{2 b}\left(500 \mathrm{MHz}, \mathrm{CDCl}_{3}\right) \quad$ S5

$\begin{array}{lll}\text { Figure S5. } & \text { APT } \text { spectrum of compound } \mathbf{2 b} & \text { S6 }\end{array}$

$\begin{array}{lll}\text { Figure S6. } & { }^{1} \mathrm{H}-{ }^{1} \mathrm{H} \text { COSY spectrum of compound } \mathbf{2 b} & \text { S7 }\end{array}$

$\begin{array}{llr}\text { Figure S7. HMQC spectrum of compound } \mathbf{2 b} & \text { S8 }\end{array}$

$\begin{array}{llr}\text { Figure S8. } & \text { UV/vis spectrum of compound } \mathbf{2 b} & \text { S9 }\end{array}$ 

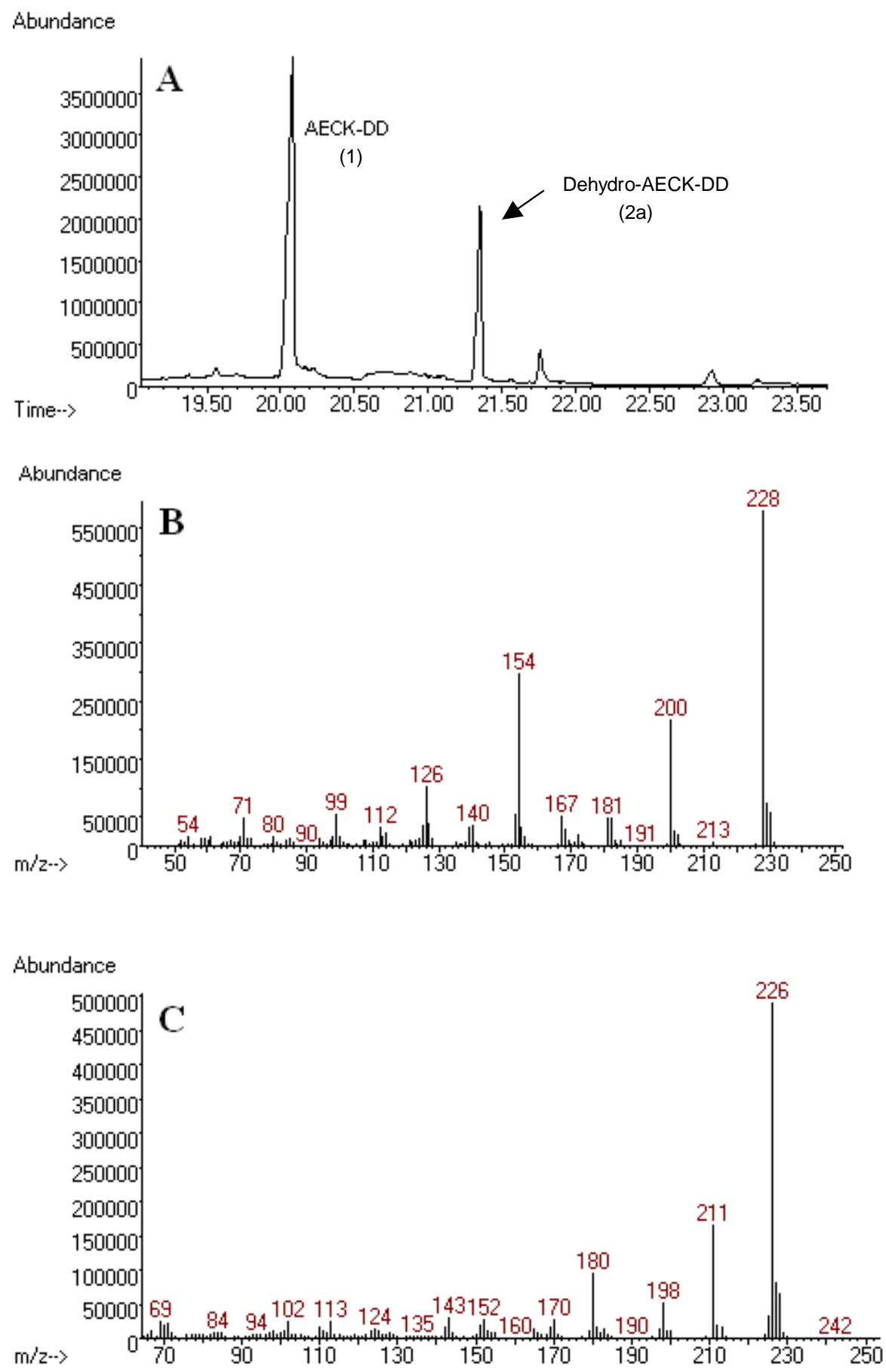

Figure S1.A: GC profile of the extract of a reaction mixture containing AECK-DD in the presence of $\mathrm{CuCl}_{2}$ /tert-butyl hydroperoxyde showing the presence of a new species $\mathbf{2 a}$

Figure S1.B: Mass-spectrum of 1

Figure S1.C: Mass spectrum of 2a 


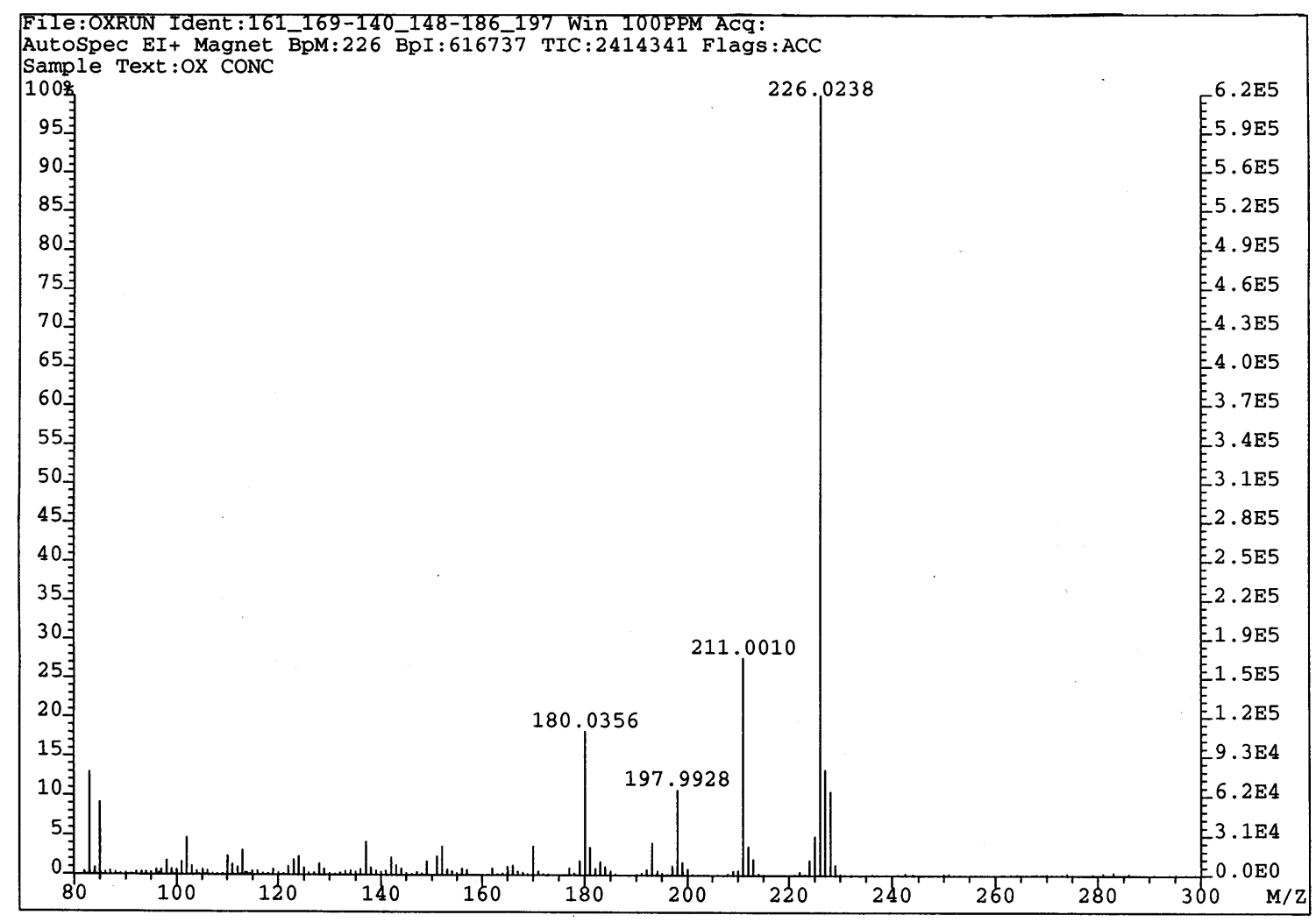

Figure S2: High Resolution Mass Spectrum of compound 2b 


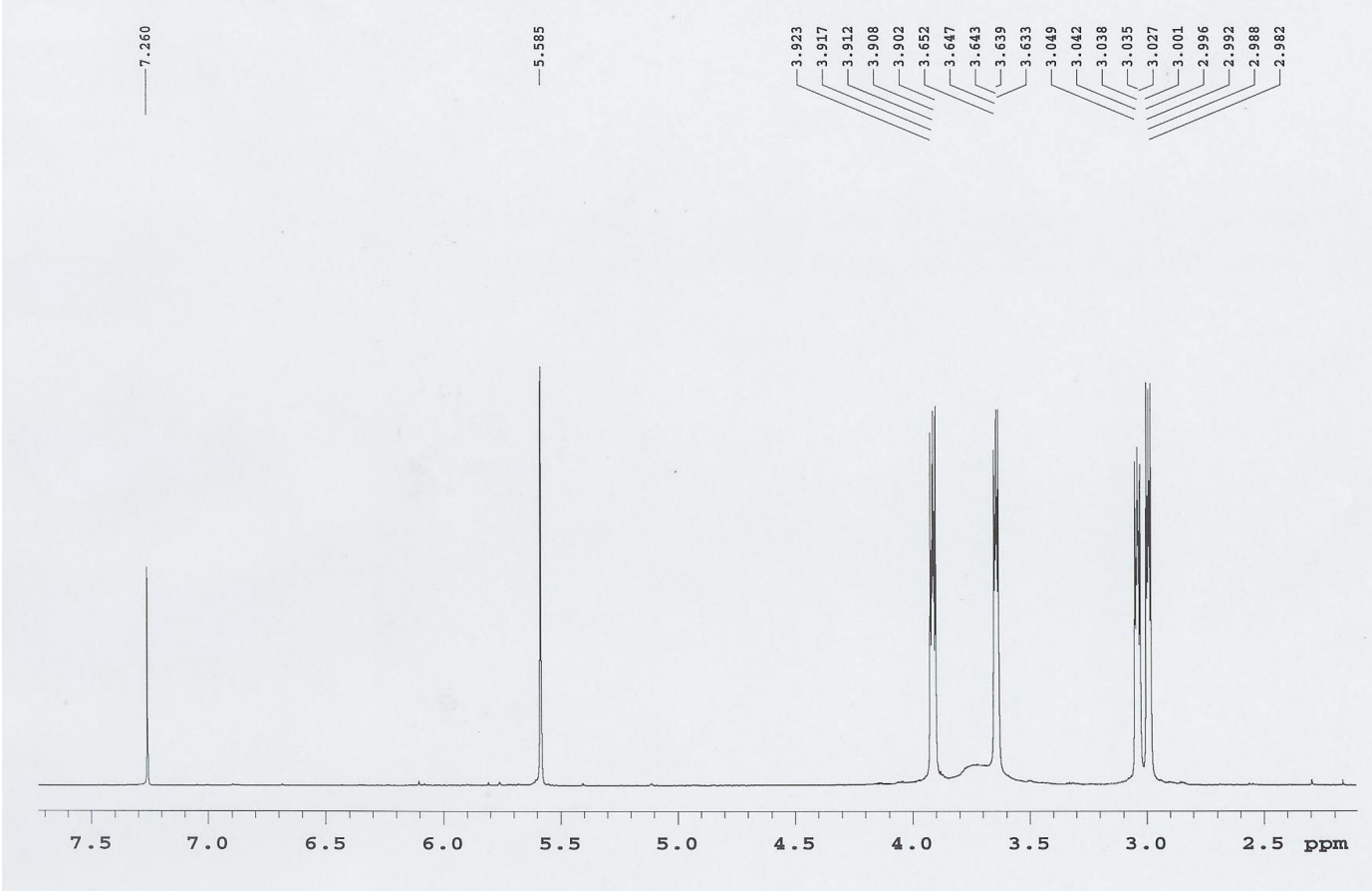

Figure S3: ${ }^{1} \mathrm{H}-\mathrm{NMR}$ spectrum of compound $\mathbf{2 b}\left(500 \mathrm{MHz}, \mathrm{CDCl}_{3}\right)$ 


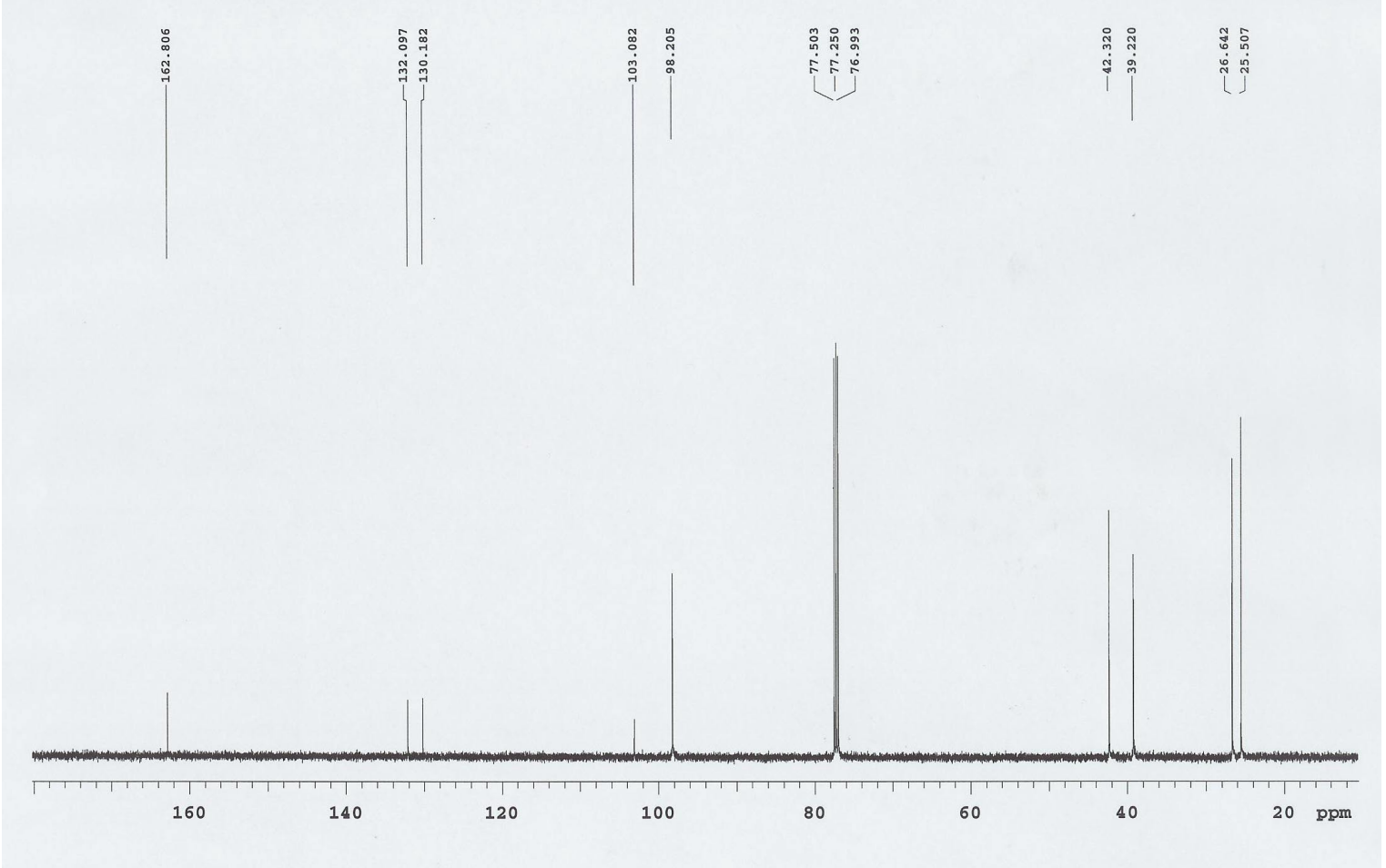

Figure S4: ${ }^{13} \mathrm{C}-\mathrm{NMR}$ spectrum of compound $\mathbf{2 b}\left(125.7 \mathrm{MHz}, \mathrm{CDCl}_{3}\right)$ 


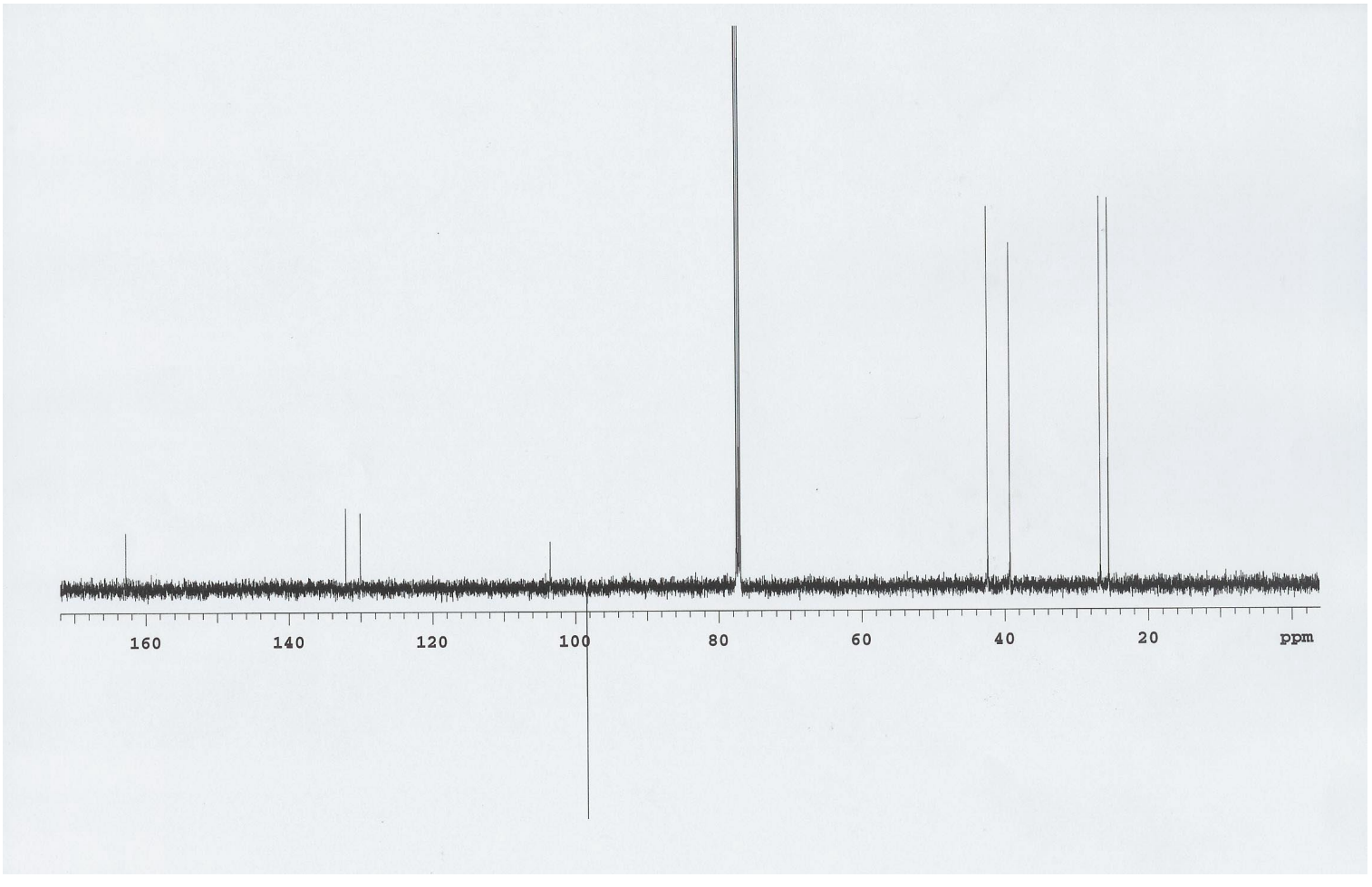

Figure S5: APT spectrum of compound $\mathbf{2 b}$ 


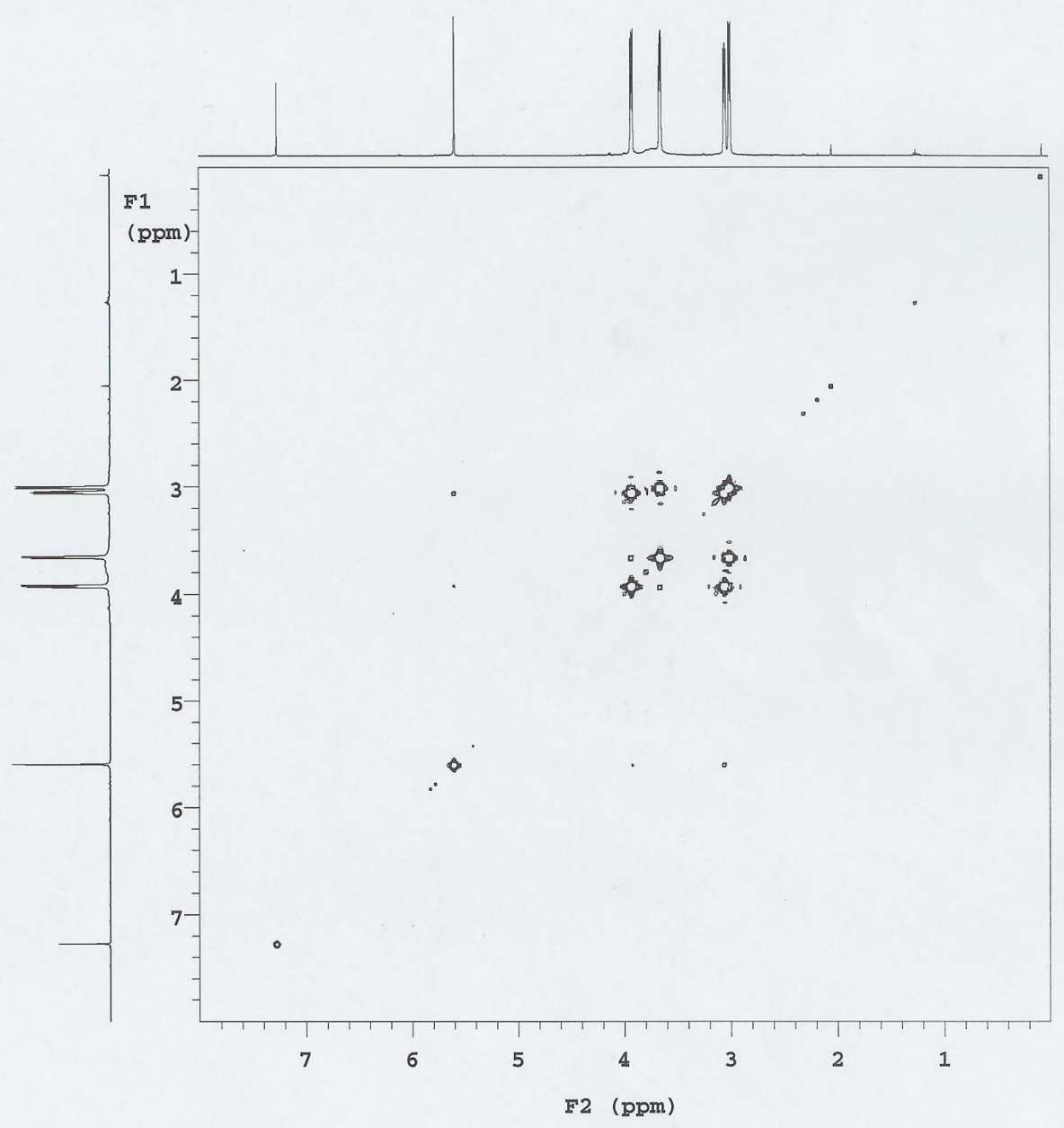

Figure S6: ${ }^{1} \mathrm{H}-{ }^{1} \mathrm{H}$ COSY spectrum of compound $\mathbf{2 b}$ 


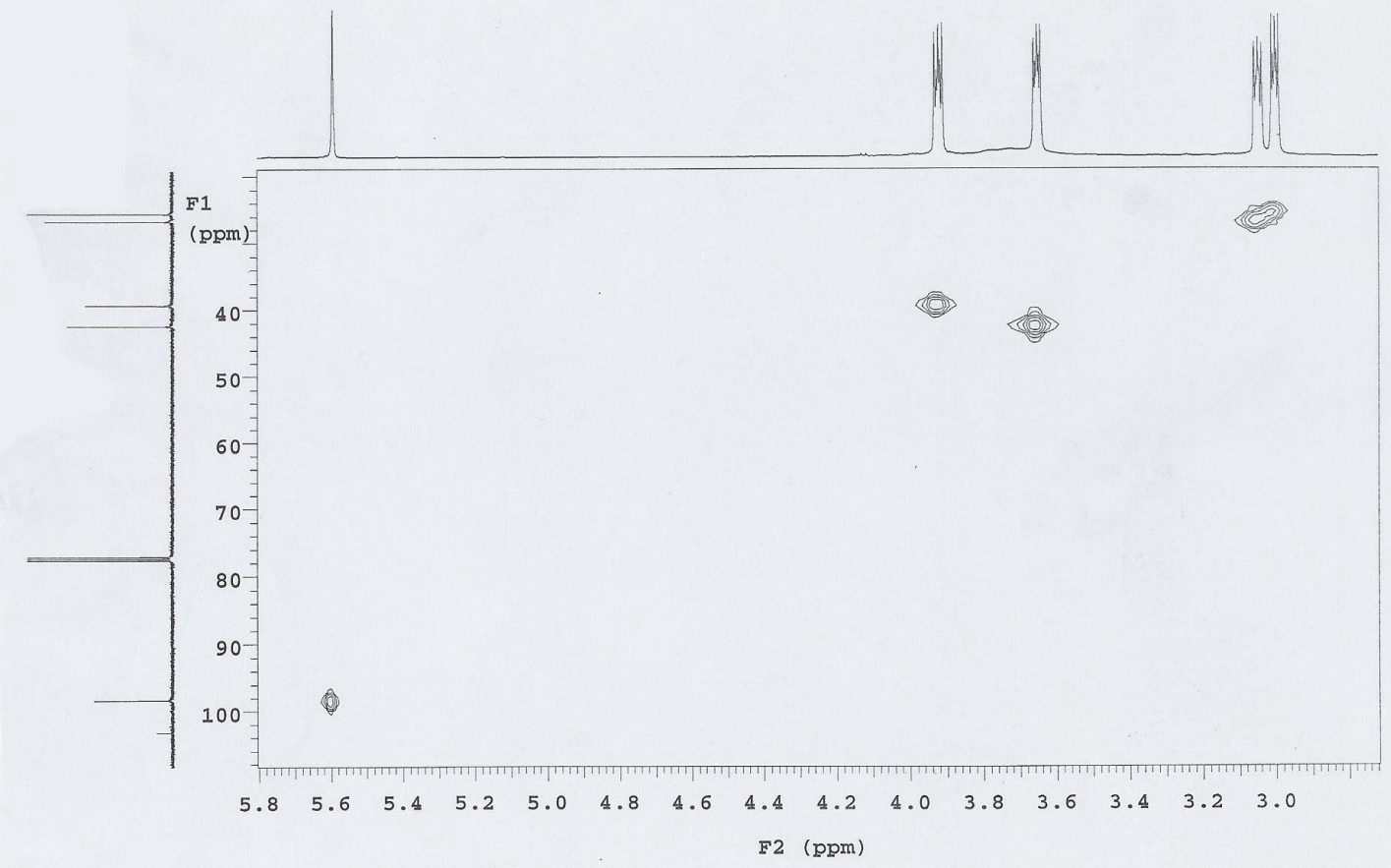

Figure S7: HMQC spectrum of compound 2b 


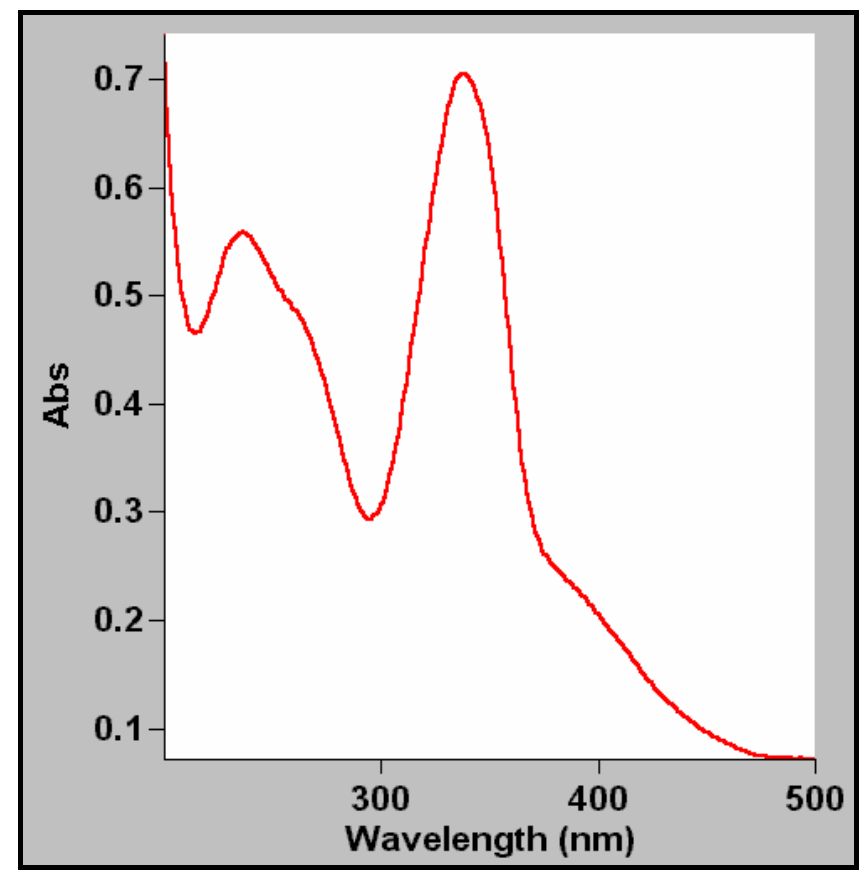

Figure S8: UV/vis spectrum of compound $\mathbf{2 b}$ 